\title{
Celebrating 50 years of Development
}

This issue marks Volume 50 of Development, the quarterly journal of the Society for International Development. Throughout these 50 years, the journal has promoted an open discussion on development theory, institutions, ideals and practices and their contribution to economic and social justice, gender equity, equality and freedom.

In this 50th Volume we take up themes that continue squarely in this tradition, looking at four pivotal issues of the coming decade: 'Democracy', 'Poverty', 'China' and 'Migration'. In addition to the usual four issues, we will have a fifth, special issue-courtesy of the publisher Palgrave Macmillan to be launched at the 50th anniversary International Congress to be held in The Netherlands 4-7 July 2007.

The 50th Volume is also an opportunity to celebrate a tradition of publishing ideas that provoke engaged debate on the different facets of transnational political, economic and social relations that make up the realm of development. From different angles 'Development' has looked critically at how to connect development policy and research with peoples realities on the ground, as well as activism and alternative thinking.

Over the years Development has published critical articles that cover the core ethical, analytical and practical debates informing the 'hot issues' among national and global development communities, civil society, social movements, policy makers, researchers and opinion makers. These are articles that speak with vision and resolve but also examine critically the ugly side of today's inequalities - the failure to end poverty, gender-based violence and social and economic insecurities, the environmental loss and the degradation of cultural identity - in order to build a vision and practice that will lead to gender equality, economic and social justice.

We would like to take this occasion to celebrate the achievements of the authors, the editors and the collective process of producing these dynamic journals every three months. We would like to thank all who contributed and supported us, including Development readers from the South and North working in research institutes, policy bureaux, international and national development NGOs and social movement networks of civil society.

We trust that Development will continue to serve readers as the flagship publication of the Society for International Development in the years to come, as it continues to promote sustained, honest and systematic analysis of development. 